\title{
Synthetic Resin Reinforcement of Timber Joints Deteriorated by Termites
}

\author{
Yamada Mikako ${ }^{1, a}$, SawadaMasamitsu ${ }^{2, b}$, Imamoto Kei-ichi $^{3, c}$, Kiyohara Chizuru $^{4, d}$ and \\ Ohtsuka Akiko, \\ 'Tokyo University of Science, Tokyo, JAPAN, a sarusarumika0905@gmail.com \\ ${ }^{2}$ Tokyo University of Science, Tokyo, JAPAN, b masayan.sawa.1120@gmail.com \\ ${ }^{3}$ Tokyo University of Science, Tokyo, JAPAN, ${ }^{c}$ imamoto@rs.tus.ac.jp \\ ${ }^{4}$ Tokyo University of Science, Tokyo, JAPAN, ${ }^{d}$ ckiyo@rs.tus.ac.jp

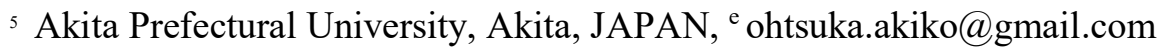

\begin{abstract}
Timber has been widely adopted as a global structural material. However, timber sometimes deteriorates due to various factors such as termite infestation, which may reduce its strength and durability. It is difficult to ascertain the degree of deterioration of timbers by visual inspection because deterioration by termites causes severe damage to the inner parts of the timber. Therefore, the damage is often discovered after the deterioration progresses. The restoration and refurbishment method currently implemented is removing the degraded parts and partially replacing them with new healthy wood. Although it is as desirable to reinforce the original part as it is to restore its strength, especially for historical timber structures, this approach has not yet been put into practical use. This study investigates the possibility of restoring timber deteriorated by termites with little changes in its appearance by using resin filling. Deterioration by termites occurs at the base of the timber. Therefore, the specimen is assumed to be the joint of a foundation and column. First, the deteriorated specimen was filled with epoxy resin, and then, the effectiveness of the filling was confirmed by a nondestructive test method using ultrasonic pulse velocity. Finally, shear strength test was performed for the joint. As a result, ultrasonic velocity significantly increased because of the resin filling. The strength of the specimen filled with epoxy resin was restored and was close to the strength of a healthy one. It was confirmed that this strengthening method with resin filling was useful for improving the structural performance of timber deteriorated by termites with little change in appearance.
\end{abstract}

Keywords: Strength, Termite Damage, Nondestructive Test, Epoxy Resin, Ultrasonic Pulse Velocity.

\section{Introduction}

The damage caused by termites is one of the main degrading factors of timber structures. Termites are active in wet conditions; hence, they can cause damage to the base of timber that is close to the ground. In addition, in timber buildings, joint strength is very important. It is clear that the deformation and strength capacity of the joint strongly affects the deformation and structural capacity of the building. Therefore, in this study, the authors focus on the reinforcement of the base joint.

The authors examine the reinforcing method of injecting synthetic resin into the deteriorated parts of the timber. The reinforcing method is characterized by a little change in appearance, as shown in Figure 2. 

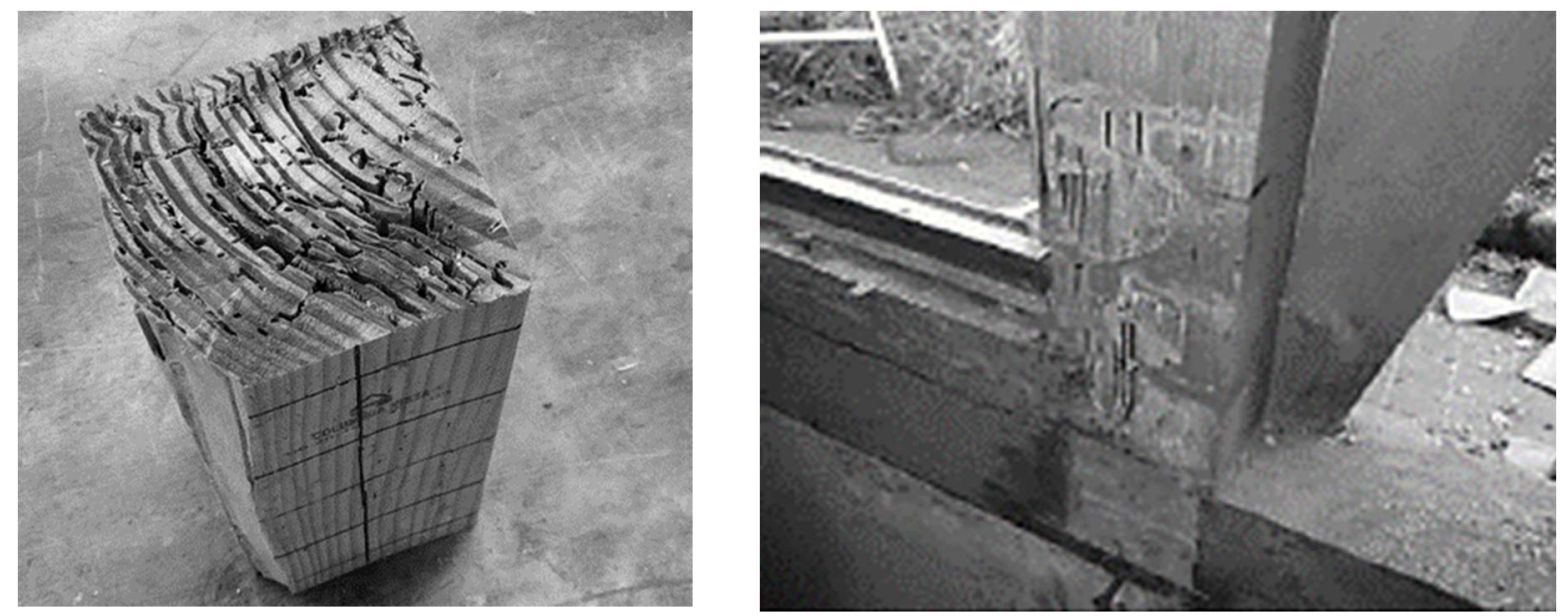

Figure 1. Timber damaged by termites. (Source: KAWATA Tasturo, 2017)
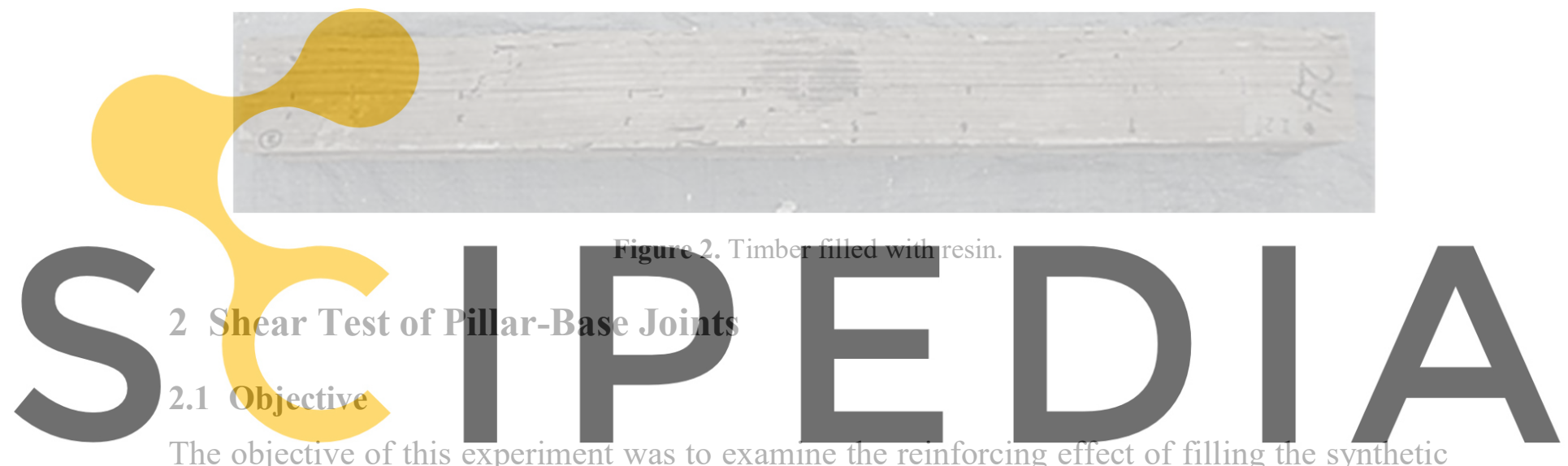

The objective of this experiment was to examine the reinforcing effect of filling the synthetic Register forip on the restoration of timbers deteriorated by termites. The reinforcing method is as follows. drilled in a staggered manner at 100-mm intervals (Figure3). Finally, using a static mixer, the synthetic resin is injected through the hole into the specimen (Figure4).

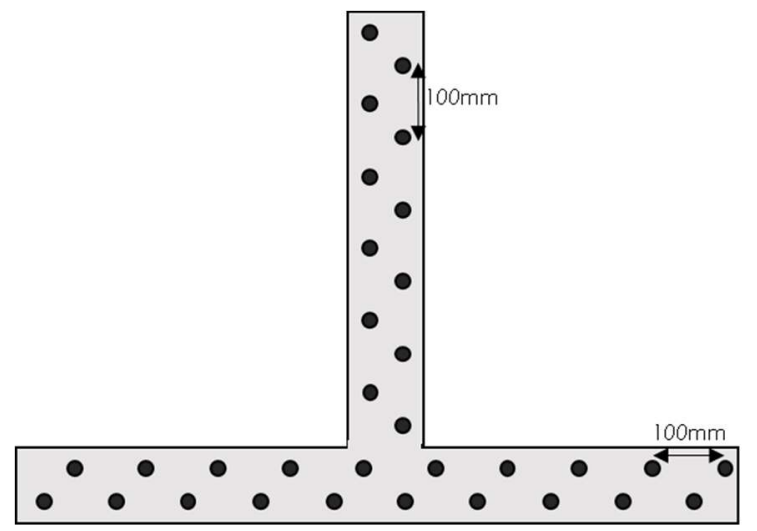

Figure 3. Image of filling hole.

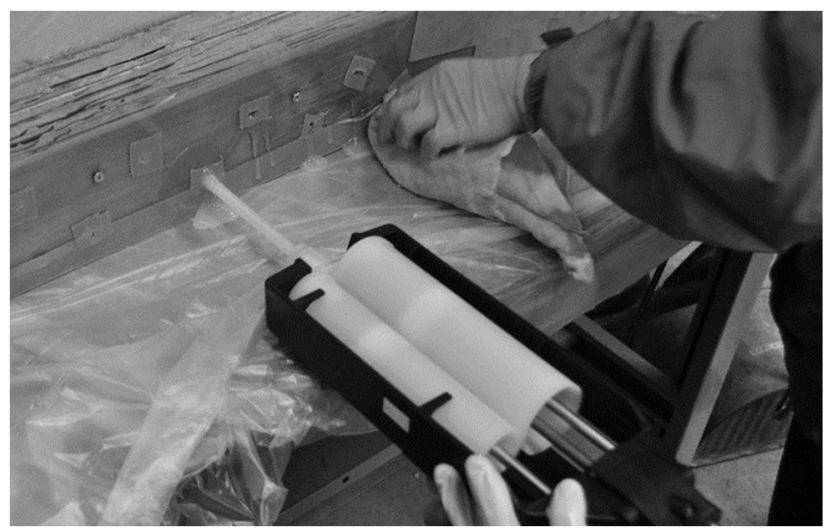

Figure 4. Resin filling work. 


\subsection{Summary of Specimens}

The specimen was prepared using Douglas fir. The dimensions of the column were $105 \mathrm{~mm} x$ $105 \mathrm{~mm}$ x $600 \mathrm{~mm}$, and those of the base were $105 \mathrm{~mm} \times 105 \mathrm{~mm} \times 1000 \mathrm{~mm}$. The joint was a stub tenon. The dimensions of the tenon were $30 \mathrm{~mm}$ x $75 \mathrm{~mm} \times 50 \mathrm{~mm}$, and those of the mortise were $30 \mathrm{~mm} \times 75 \mathrm{~mm} \times 80 \mathrm{~mm}$. Ten sets of column and base specimens were prepared, and two of them were used as control. The deterioration was carried out for four months at a test site where termites live (Figure5). The degree of damage was evaluated by the mass reduction rate before and after the damage treatment. The specimens are listed in Table 1.

Regarding the resin filling, two types of synthetic resin, epoxy resin and polyamine resin, were used to examine the change in strength depending on the type of synthetic resin. In Table 1, "Resin A" is hard type, and "Resin B" is elastic type. Three specimens were prepared and filled with resin A, and two were filled with resin B. In this test, five restored specimens were used.
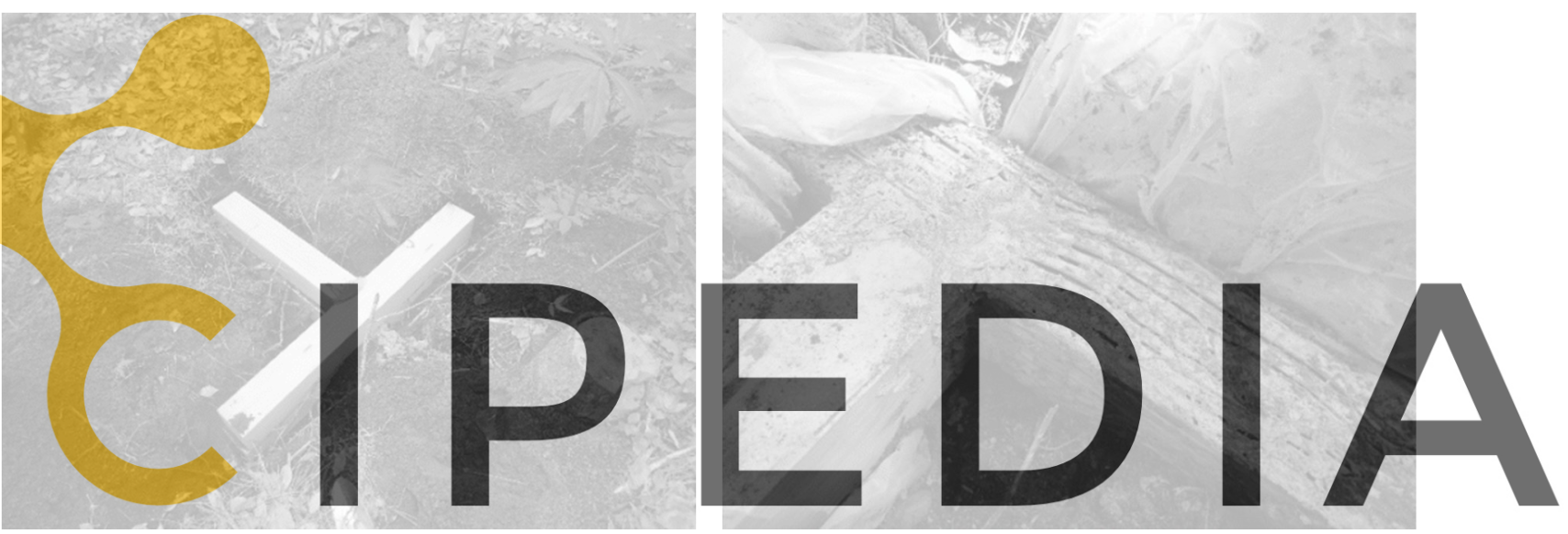

Register for free at https///Wure 5. Soil expssure due to feeding damage caused by termites . Table 1. Name of specimens and test parameters.

\begin{tabular}{|c|c|c|c|c|c|c|c|}
\hline \multirow{2}{*}{ Name } & \multirow{2}{*}{$\begin{array}{c}\text { Feeding damage } \\
\text { rate[\%] }\end{array}$} & \multicolumn{6}{|c|}{ Resin } \\
\hline & & Name & Materials & Fit ratio & Method & Tool & Feature \\
\hline $0-\mathrm{N}(1)$ & \multirow{2}{*}{0} & \multirow{5}{*}{ None } & & & \multirow{5}{*}{ - } & & \\
\hline $0-\mathrm{N}(2)$ & & & & & & & \\
\hline $10-\mathrm{N}$ & 10 & & & & & & \\
\hline $15-\mathrm{N}$ & 15 & & & & & & \\
\hline $20-\mathrm{N}$ & 20 & & & & & & \\
\hline $10-\mathrm{A}$ & 10 & \multirow{3}{*}{ A } & \multirow{3}{*}{$\begin{array}{c}\text { epoxy resin } \\
+ \text { polyamine resin }\end{array}$} & \multirow{3}{*}{$2: 1$} & \multirow{3}{*}{ filling } & \multirow{3}{*}{$\begin{array}{l}\text { static } \\
\text { mixer }\end{array}$} & \multirow{3}{*}{ hard } \\
\hline $15-\mathrm{A}$ & 15 & & & & & & \\
\hline $20-\mathrm{A}$ & 20 & & & & & & \\
\hline 10-B & \multirow{2}{*}{10} & \multirow{2}{*}{ B } & \multirow{2}{*}{$\begin{array}{c}\text { epoxy resin } \\
+ \text { polyamine resin }\end{array}$} & \multirow{2}{*}{$3: 2$} & \multirow{2}{*}{ filling } & \multirow{2}{*}{$\begin{array}{l}\text { static } \\
\text { mixer }\end{array}$} & \multirow{2}{*}{ elasticity } \\
\hline $15-\mathrm{B}$ & & & & & & & \\
\hline
\end{tabular}




\subsection{Loading Method and Loading Protocol}

The experimental setup of a joint member with a column and base is shown in Figure 6. The base was fixed to the foundation steel member by passing bolts through the steel plate on the left and right sides and tightening each bolt with a strength of $20 \mathrm{~N}$. In addition, by assuming the actual building weight, an axial load of $10 \mathrm{kN}$ was applied to the column through a drop jig. Then, a positive and negative cyclic load testing was applied $500 \mathrm{~mm}$ height from the upper surface of the base portion. The applied rotation angle $(\theta)$ was $1 / 450,1 / 300,1 / 200,1 / 150,1 / 100$, $1 / 75$, and $1 / 50$ [rad] in each three cycles, and then $1 / 30,1 / 15$, and $1 / 10$ [rad].

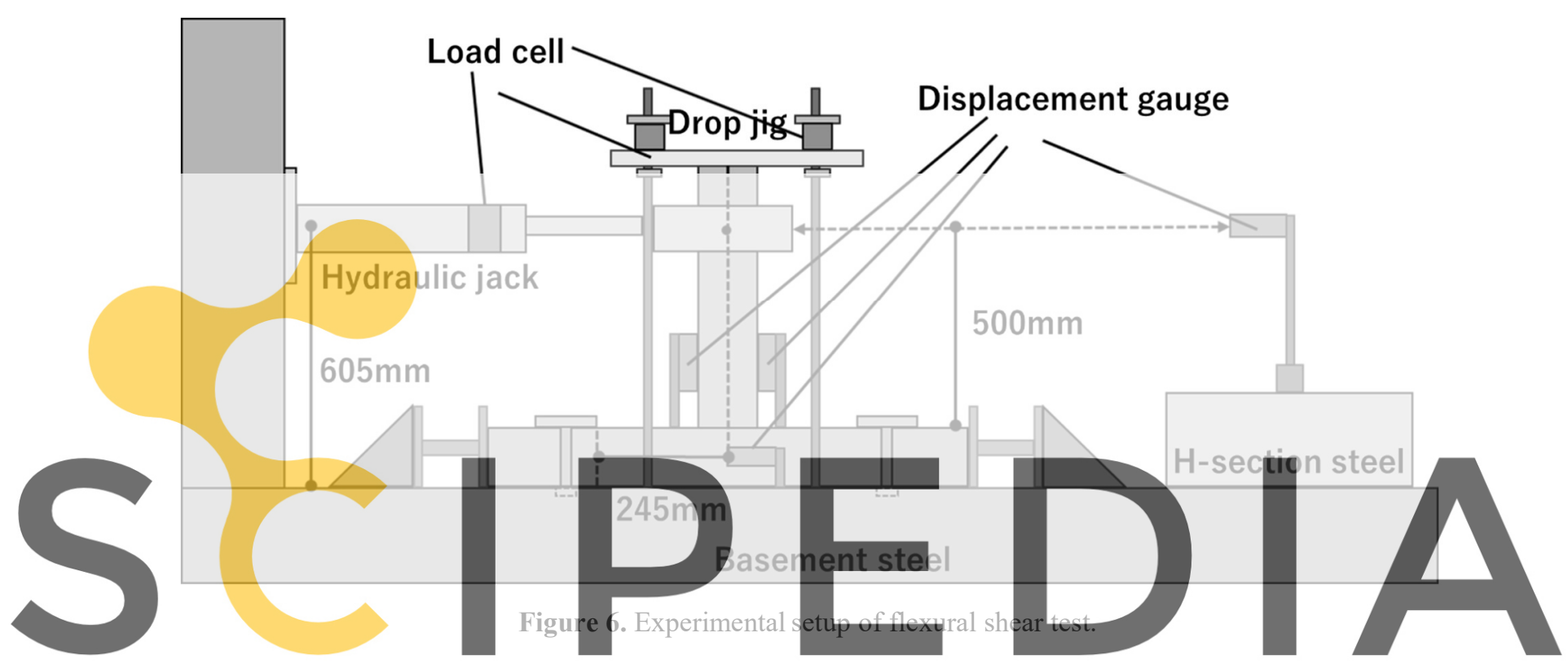

2.4 Result of Experiment

Register for free at https//www scipedia.com to download the version without the watermark

"0" means without termite damage. "10", "15," and " $20 "$ represent $10 \%, 15 \%$, and $20 \%$ weight

losses due to termite damage, respectively. For $0-\mathrm{N}, 10-\mathrm{N}$, and $20-\mathrm{A}$, the bending moment was increased up to $1 / 30 \mathrm{rad}(0.03 \mathrm{rad})$, and for the others, it was increased up to $1 / 50 \mathrm{rad}(0.02 \mathrm{rad})$. It can be observed that the strength significantly decreased with an increase in damage rate. Furthermore, the decreased strength was significantly restored by resin reinforcement. 

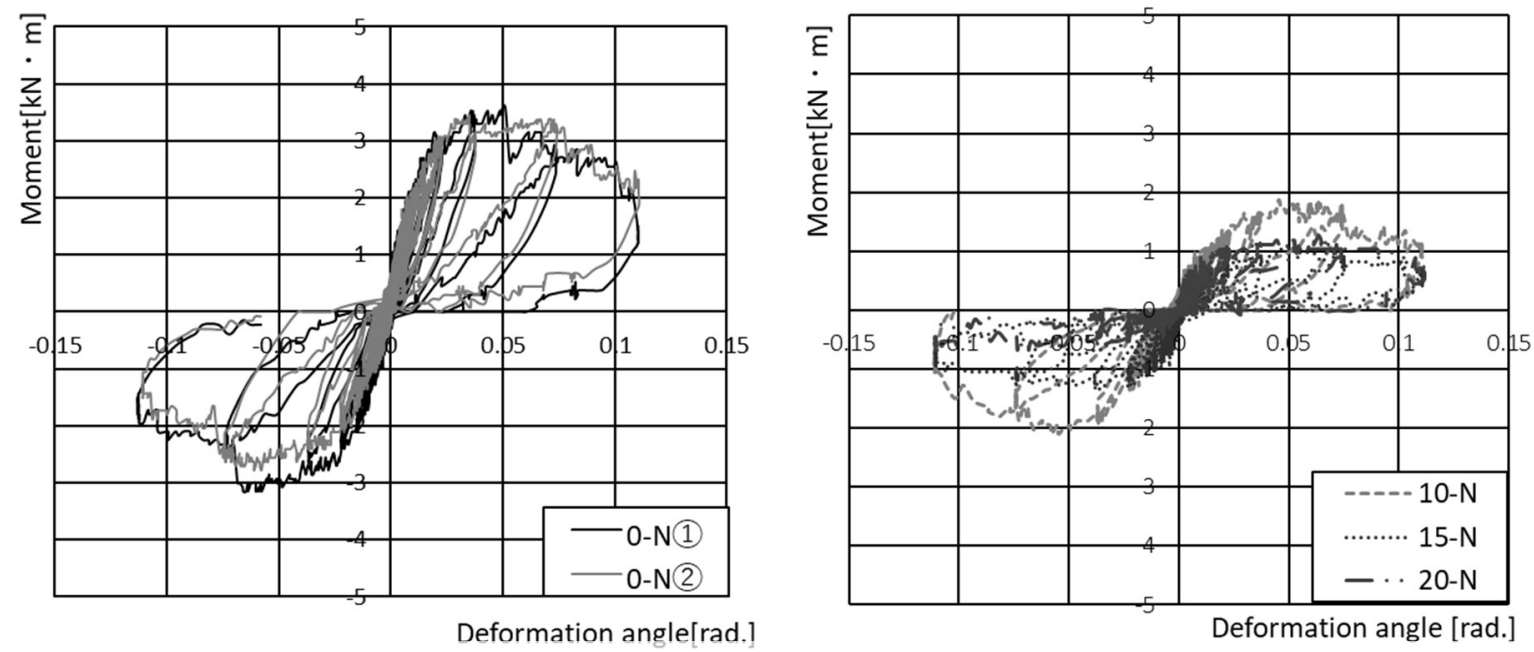

control materials
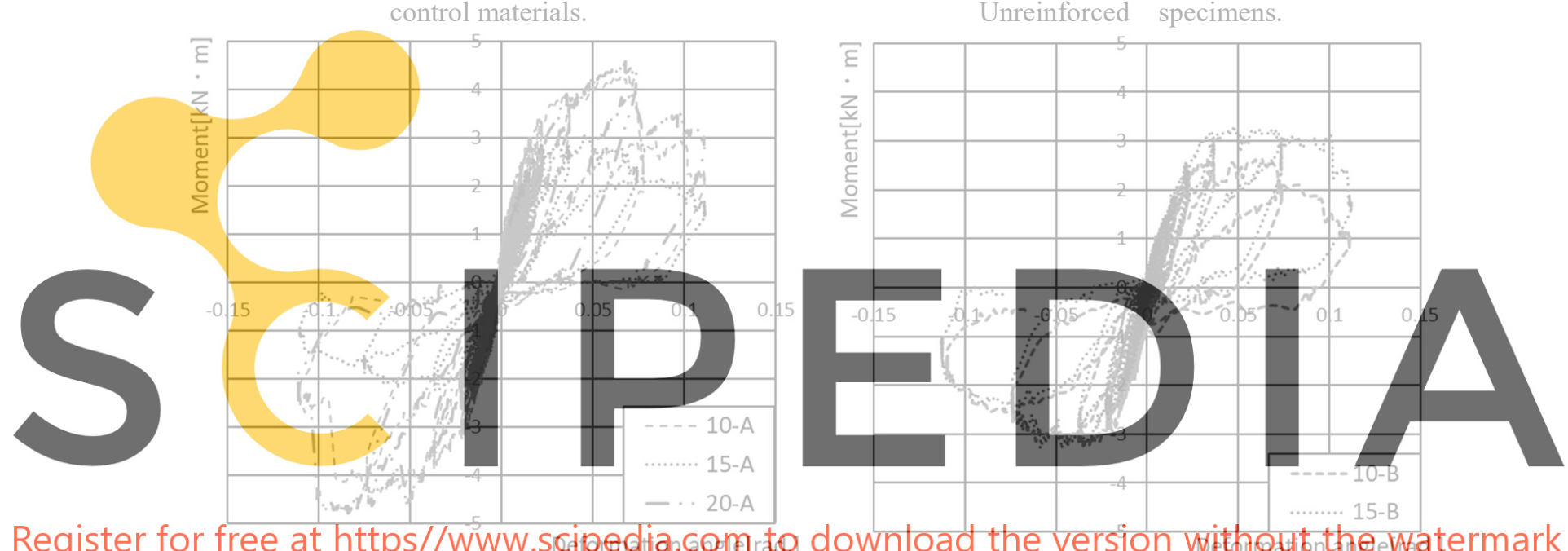

Register for free at https//wWW.Scipedia
\[ \text { Specimens filled with resin A. } \]

Specimens filled with resin B.

Figure 7. Relationship between the moment and deformation angle.

The volume ratio of the resin to be filled into the specimen was calculated by using its density information and the mass reduction rate of the deteriorated specimens, as shown in Figure 8. All specimens were filled with resin as described above, and a significant difference in the filling rate for each specimen was confirmed.

Figure 2 shows the skeletal curve between the moment and the deformation angle. Regarding the specimens without filling, the values of both rigidity and strength were lower than that of $0-\mathrm{N}$ as a reference specimen. Regarding the specimens filled with resin A, a significant recovery in both rigidity and strength was observed. The rigidity and strength of 10-A and 20-A were higher than those of $0-\mathrm{N}$. The filling ratio of $15-\mathrm{A}$ was about $10 \%$. Therefore, it was observed that there would not be a considerable recovery of rigidity and strength because of insufficient filling. Overall, when the deteriorated timbers were filled with resin A, they exhibited a possibility of recovery in rigidity and strength. In contrast, the strength and rigidity of the specimens filled with resin $\mathrm{B}$ did not match that of $0-\mathrm{N}$. They exhibited higher strength and 
rigidity than those without filling for the same feeding rate.

It was observed that the strength and rigidity of $10-\mathrm{B}$ did not recover because of insufficient filling. In the case of $15-\mathrm{B}$, which had the highest filling rate, a complete recovery was not confirmed. This result might indicate that the low elasticity of resin was not effective for reinforcement. Despite the filling rate of approximately 40\%, 10-A exhibited similar rigidity and strength to $0-\mathrm{N}$. If the filling level increased beyond a certain value, it might be unnecessary to fill the specimen completely. The variation in the filling rate was caused by bubbles generated due to the heat reaction of resin during curing. It will be necessary to evaluate the effect of the filling rate, filling position, and curing temperature of the resin on the mechanical properties of deteriorated timber members in the near future.

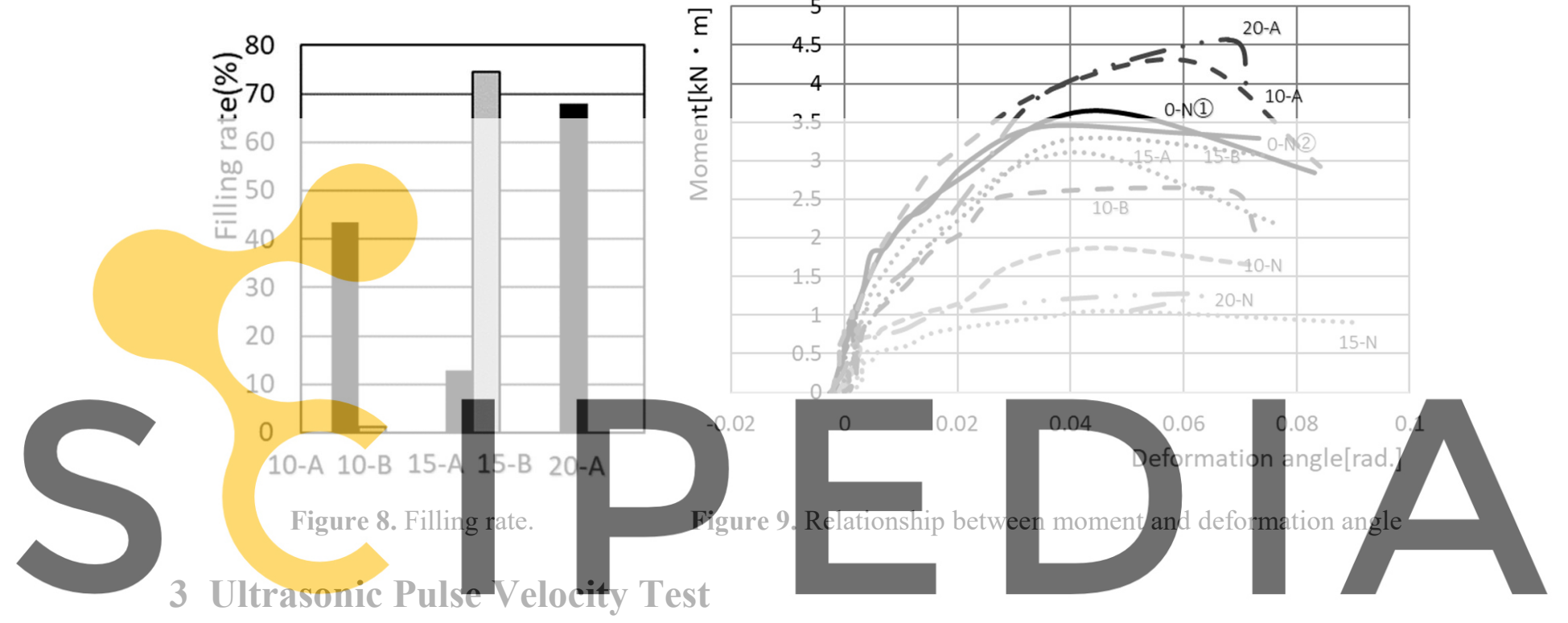

\section{Register fon freenat https//www.scipedia.com to download the version without the watermark}

The damage caused by termites is significantly hidden inside the timber and often invisible. The ultrasonic testing machine (pundit) shown in Figure10, would be an effective method for detecting internal defects in timber. Ultrasonic pulse velocity can be measured by sandwiching both sides of the specimen. Filling conditions and restoration might be confirmed by evaluating the rate of change in ultrasonic velocity before and after resin filling.

\subsection{Deterioration Detection}

Figure11 shows the relationship between the mass reduction rate and the reduction in ultrasonic velocity before and after damage treatment. The reduction rate of ultrasonic pulse velocity is defined as the rate of the velocity to the velocity of the sound timber. A high correlation was observed between the mass loss rate and the reduction rate of ultrasonic velocity, as shown in Figure 11. Hence, the mass loss rate can be identified by measuring the ultrasonic pulse velocity. As a result, it was suggested that the ultrasonic pulse velocity test might be effective in evaluating the deterioration by termites. 


\subsection{Check of Filling}

The relationship between the filling rate and the increased rate of ultrasonic velocity is shown in Figure12, a high correlation was observed between them. Hence, the effectiveness of resin filling was confirmed by an increase in the ultrasonic pulse velocity

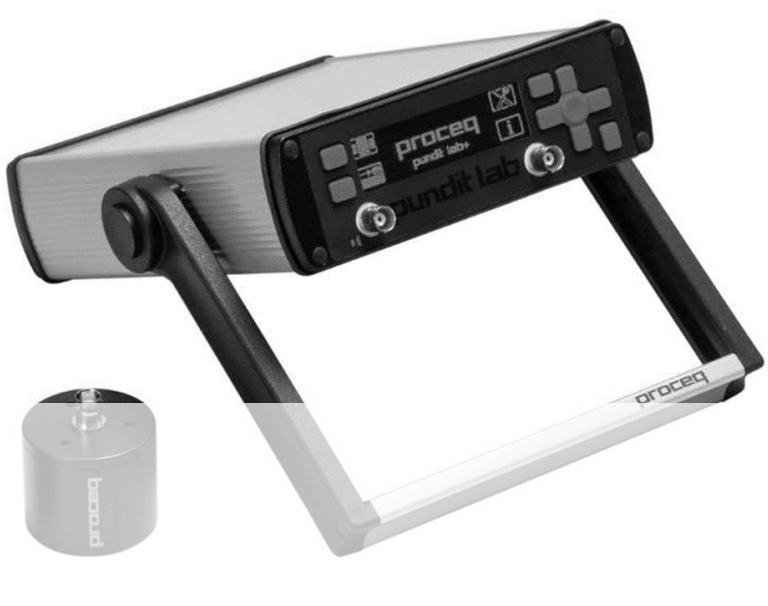

Figure 10. Ultrasonic testing machine. (pundit)

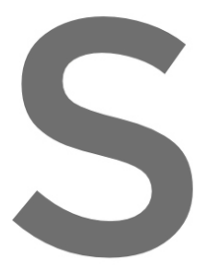

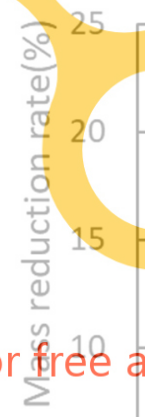

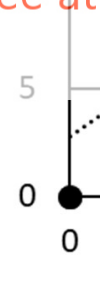

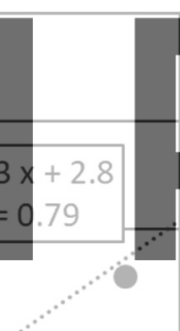
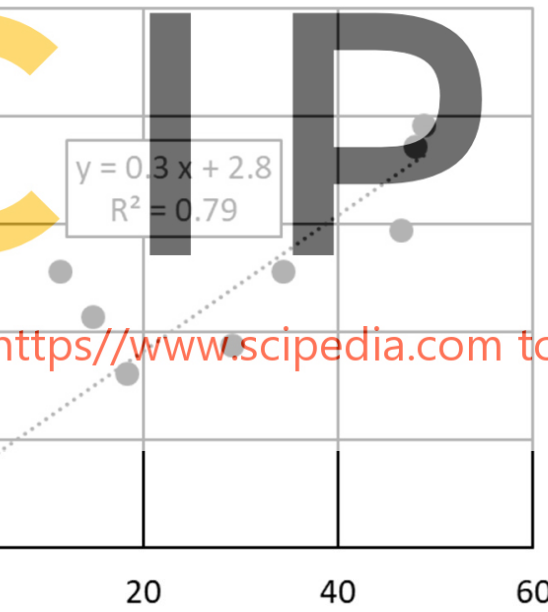

Reduction rate of ultrasonic velocity $(\%)$

Figure 11. Relationship between mass reduction rate and reduction of ultrasonic velocity before and after feeding damage.

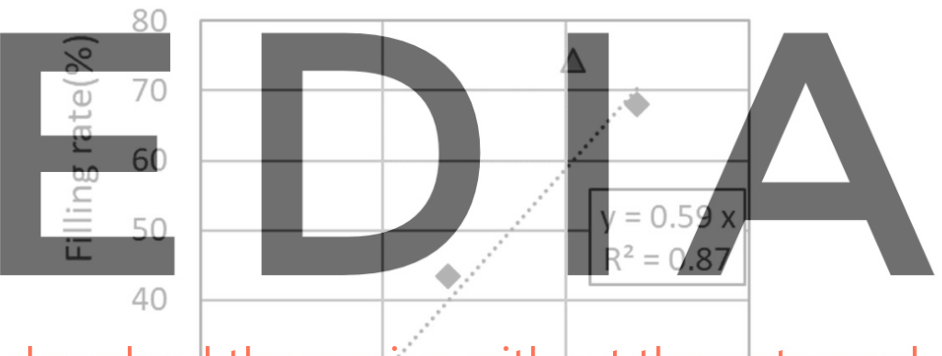

60

$$
\text { C }
$$

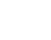

(1)

\section{Conclusion}

The following conclusion were obtained in this study:

- Throughout the shear test of pillar-base joints, filling the deteriorated timbers with the hard type resin led to the recovery of rigidity and strength. Hence, the effectiveness of resin filling as a reinforcement method was demonstrated. 
- All test bodies were filled with resin in a staggered manner, and a significant variation in the filling rate for each specimen was confirmed. Even though the filling rate was approximately $40 \%$, there was a specimen that showed rigidity and strength close to 0 -N. If the filling level increases beyond a certain value, it might be unnecessary to completely fill the specimen. It will be necessary to examine the effect of the filling rate, filling position, and curing temperature of the resin on the mechanical properties of deteriorated timber members.

- A high correlation was confirmed between the mass loss rate and the reduction rate of ultrasonic velocity. Thus, it was suggested that the ultrasonic pulse velocity test might be effective in evaluating the deterioration by termites.

- A high correlation was observed between the filling rate and the increased rate of ultrasonic velocity. Therefore, the filling rate can be confirmed by an ultrasonic pulse velocity test in a non-destructive manner.

References

Architectural Institute of Japan (2018). Deformation and Fracture in Timber Structure, Maruzen Publishing Co., Ltd.

Goromaru Shuhei (2018). Proposal of reinforcement method by missing exploration and resin filling in deteriorated wooden buildings, Architectural Institute of Japan, Vol.88, pp.45-48

Higuchi Seiji (2003). A Retrospection: Early Examples of the Application of Synthetic Resins for the Conservation of Japanese Cultural Properties, Report of the National Museum of Ethnology, Vol.36, pp.53-91

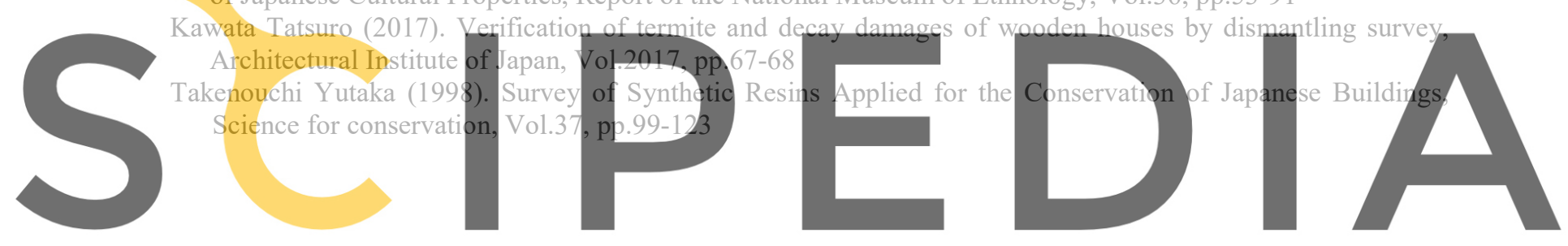

